\title{
EDITORIAL
}

\section{Um Instrumento de Fomento ao Conhecimento Científico}

\author{
A Tool of Scientific-Knowledge Development
}

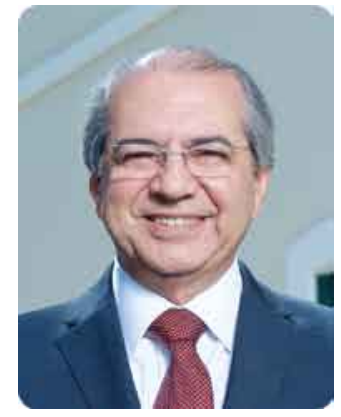

\author{
Roberto Sá Menezes ${ }^{1}$ \\ ${ }^{\prime}$ Provedor da Santa Casa da Bahia; Salvador, Bahia, Brasil
}

A primeira edição da Revista Científica do Hospital Santa Izabel (HSI) foi lançada em 2014, àquela época com o nome de "Revista de Saúde do Hospital Santa Izabel". Há três anos, a publicação ganhou o nome atual e, mais recentemente, tornou-se indexada, o que comprova seu padrão de qualidade, o cumprimento da periodicidade e o compromisso com a distribuição dos exemplares.

Produzida sob a supervisão da Diretoria de Ensino e Pesquisa do HSI, esta revista vem sendo um importante instrumento para a propagação dos avanços da ciência médica produzida por profissionais que atuam no Santa Izabel. Com a recente indexação, o periódico ganha mais visibilidade, nacional e internacional, com rapidez e sistematização.

Com a Revista Científica do Hospital Santa Izabel, ainda tem sido possível contribuir para que profissionais de saúde e especialistas de outras áreas que exploram o desenvolvimento de tecnologias em prol dos avanços da saúde gerem e tornem públicos novos conhecimentos.

Nos últimos anos, a Santa Casa da Bahia seguiu com investimentos no desenvolvimento e contribuição de protocolos de pesquisa. Especificamente em 2019, o Núcleo de Pesquisa do Hospital Santa Izabel conduziu estudos em cardiologia, reumatologia, pneumologia e oncologia.

A maior parte desses estudos - hoje eles contabilizam um total de 29, com acompanhamento a 150 pacientes - é internacional e multicêntrica, patrocinada por indústrias farmacêuticas de renome. Esta condição atesta o reconhecimento do Hospital Santa Izabel enquanto centro de pesquisa relevante.

Às vésperas de encerrar meu segundo mandato como provedor da Santa Casa da Bahia, registro o orgulho em ter acompanhado, nos últimos seis anos, a intensa atividade de produção científica do Hospital Santa Izabel, que tão

Correspondence addresses: Roberto Sá Menezes robertosamenezes@santacasaba. org.br / robertosamenezes@ gmail.com

Copyright (C) 2019 by Santa Casa de Misericórdia da Bahia. All rights reserved. ISSN: 2526-5563 bem corrobora a tradição da instituição em inovações. Sempre imprescindível destacar e lembrar que no Santa Izabel ocorreram as primeiras pesquisas em busca da cura da Doença de Chagas no mundo.

Parabenizo cada um dos investigadores do Núcleo de Pesquisa do Hospital Santa Izabel, todos os autores que até agora assinaram artigos nesta Revista Científica e todos que se envolveram com a geração e fomento de conhecimento científico na entidade. Em especial, cumprimento o Prof. Dr. Gilson Feitosa, diretor de ensino e pesquisa do Santa Izabel e que vem liderando com extrema competência, compromisso e ética este trabalho que tem alcançado tantas conquistas. 